\title{
Development and Validation of a New Method to Monitor and Control the Training Load in Futsal: the FUTLOC Tool
}

\author{
D. Berdejo-del-Fresno* \\ England Futsal National Squad, The Football Association and The International Futsal Academy (United Kingdom) \\ *Corresponding author: daniberdejo@gmail.com
}

Received March 12, 2015; Revised March 22, 2015; Accepted March 25, 2015

\begin{abstract}
The main objective of a coach is to optimise athletic performance. The best performance improvements come from prescribing an optimal dose of physical training with proper recovery periods to allow for the greatest adaptation before competition. The main objective was to develop and validate a new, inexpensive, easy, noninvasive, real time tool to control and monitor the training load in futsal: the FUTLOC tool. Sixteen elite male futsal players from a national team volunteered to participate in this study $(24.75 \pm 3.36$ years old, $176.21 \pm 0.70 \mathrm{~cm}, 71.50$ $\pm 8.18 \mathrm{~kg}$, BMI of $23.17 \pm 2.22$, and $60.11 \pm 2.99 \mathrm{ml} / \mathrm{kg} / \mathrm{min}$ of $\mathrm{VO}_{2}$ max. Training load was controlled and monitored daily with the FUTLOC tool. The RPE was measured using the 6-20 Borg scale. The Pearson's product moment correlation between the means of intensity, RPE, training load and equivalent training load showed an excellent concordance $(>0.75)$. To conclude, based on the results in this study and the literature reviewed, the FUTLOC tool seems to be a good method to control global internal training load in futsal. This method does not require any expensive equipment and may be very useful and convenient for coaches to monitor the internal training load of futsal players.
\end{abstract}

Keywords: RPE, periodisation, team sports, intensity

Cite This Article: D. Berdejo-del-Fresno, "Development and Validation of a New Method to Monitor and Control the Training Load in Futsal: the FUTLOC Tool.” American Journal of Sports Science and Medicine, vol.

3, no. 1 (2015): 23-27. doi: 10.12691/ajssm-3-1-4.

\section{Introduction}

The main objective of a coach is to optimise athletic performance [1]. The best performance improvements come from prescribing an optimal amount of physical training with proper recovery periods to allow for the greatest adaptation before competition [1,2]. However, for coaches of team sports, there are few simple methods of controlling training loads (TL). Kelly and Coutts [3] affirmed that a common problem for coaches of team sports is determining the appropriate TLs to be prescribed during the competition phase of the season. Factors such as the quality of the opposition, the number of training days between matches, and any travel associated with playing away games all influence the between-match periodisation of TLs.

Many different methods of recording TLs in sports have been reported. Some of these methods have included measurement of heart rates [4], distance covered during training [5], weights lifted, repetitions completed, and training time. The session-RPE method to monitor TL requires each athlete to provide a Rating of Perceived Exertion (RPE) for each exercise or session along with a measure of training time [6,7]. Another method is the Training Impulse (TRIMP) method, proposed by Bannister et al. [8] and based on the training time and average heart rate. This approach is very simple; however, it does not distinguish between different levels of training. Therefore, it has been mainly used to determine general load in aerobic-endurance sessions, which is the reason why it was later modified by Banister [9] and became based on the increase in heart rate, gradually measured. It is calculated as the duration (in minutes) multiplied by an intensity factor which is differently defined for men and women. Due to its complexity, several authors have tried to simplify it $[10,11,12]$. Yet all the attempts are still quite complex mathematically. The TRIMP training zones method was developed by Edwards [13] and is characterised by the assignment of a coefficient of intensity to five HR zones expressed as a \% of HRmax. The zone number is used to quantify training intensity; TRIMP is calculated as the cumulative total of time spent in each training zone. The zone TRIMP calculation method can distinguish between training levels while remaining mathematically simple; however, this can only quantify aerobic training and it does not allow quantification of strength, speed, anaerobic, and technical sessions. Finally, other authors, as well as Edwards [13], have tried to design further methods that are based on the training zones. One of them is the Index of Overall Demand or Intensity, developed by the Romanians Iliuta and Dimitrescu [14]. They suggested multiplying exertion length by the HR mean expressed in 
percentages of maximum or Reserve HR, and dividing it by total training time. Mujika et al. [15] introduced the concept of training units based on the quantification of training zones by blood lactate. The units were proposed to quantify training load in swimmers. To our knowledge, we have not found any studies of team sports that make use of the quantification of training zones by training units, as supported by Mujika et al. [15]. The Work Endurance Recovery (WER) method created by Desgorces et al. [16] to control the TL in intermittent sports constitutes another alternative method, although it uses a very difficult equation. Finally, the EPOC method basically consists on the excess oxygen consumed during recovery from exercise, as compared to resting oxygen consumption. The model uses a mathematical equation developed by Saalasti [17]. This method has been shown as an alternative solution to determine TL with minimally invasive procedures, such as wearing a chest band [18]. With EPOC, the TL of each individual player can be monitored and the training program adjusted, like Firstbeat Technologies Ltd [19] have shown in soccer.

Nevertheless, all the previous tools are either too expensive (the EPOC model involves heart rate monitors, as well as a special SUUNTO software) or not able to work in real time or until the training session has finished (RPE, TRIMP, TRIMP zones, or WER). Besides, most of them involve complex calculations or equations, and were designed to be used in individual sports. These are the main reasons why in team sports the TL has generally been calculated using the RPE method or the TRIMP method $[20,21,22,23,24]$. This way, the TL is calculated once the training session has finished, avoiding the chance of receiving feedback in real time about the TL, as well as the opportunity to modify the session in that moment.

Moreover, since all the quantification methods are imperfect by nature (and so is the present model), the main objective of this study was to develop and validate an inexpensive, easy, non-invasive, real time tool to control and monitor the TL in futsal: the FUTLOC tool (Futsal Training Load Control Tool) [25], a method that can be used for all teams, regardless of gender, level or budget.

\section{Methods}

\subsection{Participants}

Sixteen elite male futsal players from a senior national futsal team volunteered to participate in this study after having signed the corresponding informed consent. This study was approved by the local Ethics Committee and conducted in accordance with the guidelines of the revised Declaration of Helsinki.

\subsection{Anthropometric Tests}

Anthropometric measures were taken following the Lohmann et al. [26] instruction. Standing height was measured with a precision of $0.1 \mathrm{~cm}$ with a stadiometer and a tape measure, respectively (SECA Ltd, model 220, Germany). Body mass (kg) was recorded with a scale SECA (SECA Ltd, Germany) to the nearest $100 \mathrm{~g}$, the subjects wearing light, indoor clothing and no shoes. The Body Mass Index (BMI) was calculated using the Quetelet formula.

\subsection{Training Load}

Training load was controlled and monitored daily with the FUTLOC tool. The FUTLOC tool is a software based on the BATLOC tool [27], an instrument to control and monitor the TL in basketball. The pilot FUTLOC project started in the season 2010-2011 within the context of an English male professional futsal team competing in the The FA Futsal League $(n=14)$. Since then, the FUTLOC tool has been developed, and the final version has been applied and assessed in a national futsal team ( $\mathrm{n}=16)$. The total individual sessions analysed were 800 .

\subsection{Softaware Development}

\subsubsection{Exercise Training Load}

The FUTLOC tool has been designed with the Microsoft Excel software. The first step was to give a TL value between 1 (lower TL) and 28 (higher TL) to each court exercise. The values were assigned using a modification of the tool designed by Refoyo [28]. Each exercise was assessed taking into account the following four aspects: heart rate, density, opposition, and distance (Table 1). These four aspects cover the TL components (volume, intensity, density, and complexity) and the TL dimensions (cognitive, metabolic, and neuromuscular) proposed by Refoyo [28]. Following Refoyo [28], the cognitive dimension would be the opposition, the metabolic dimension would be the heart rate, and the density and neuromuscular dimensions would correspond to the distance and the changes of direction/sprints. The heart rate variable was calculated as the average heart rate after having practiced each exercise for 10 minutes. The density variable is defined as the relation between work time and rest time in each exercise. The opposition variable is related to the number of players involved in each exercise. Exercises that require $5 \times 5$ actions are the hardest tasks, while exercises such as $5 \times 0$ or $4 \times 0$ are the easiest, based on the perception-decision-execution cycle $[29,30]$. Obviously, the distance variable is measured by the number of futsal courts involved in the exercise. For example, the exercise " $5 \times 52$ courts" obtained the following values: 8 points in the heart rate aspect, 9 in density, 10 in opposition or number of players involved, and 7 in distance (mean: 8.5 points). Thus, with a simple rule of three, this exercise showed a TL of 23.8 $[(28 * 8.5) / 10=23.8]$. This means that if any coach performs the exercise " $5 \times 52$ courts" for 10 minutes, the TL will be 23.8. If the exercise is practiced for 20 minutes, the TL will be 47.6 .

Table 1. Assessment of each exercise using the four variables

\begin{tabular}{|cc|cc|cc|cc|}
\hline \multicolumn{2}{|c|}{ HEART RATE } & \multicolumn{2}{|c|}{ DENSITY } & \multicolumn{2}{c|}{ OPPOSITION } & \multicolumn{2}{c|}{ DISTANCE } \\
\hline 10 & $100 \%$ & 10 & Continuous & 10 & $5 \times 5$ & 10 & Continuous \\
\hline 9 & $95 \%$ & 9 & $4 / 1$ & 9 & $5 \times 4$ or $4 \times 5$ & 9 & 4 courts \\
\hline 8 & $90 \%$ & 8 & $3 / 1$ & 8 & $4 \times 4$ & 8 & 3 courts \\
\hline 7 & $85 \%$ & 7 & $2 / 1$ & 7 & $4 \times 3$ or $3 \times 4$ & 7 & 2 courts \\
\hline 6 & $80 \%$ & 6 & $1 / 1$ & 6 & $3 \times 3$ & 6 & 1 \& $1 / 2$ courts \\
\hline 5 & $75 \%$ & 5 & $1 / 2$ & 5 & $3 \times 2$ or $2 \times 3$ & 5 & 1 court \\
\hline 4 & $70 \%$ & 4 & $1 / 3$ & 4 & $2 \times 2$ & 4 & $2 / 3$ court \\
\hline 3 & $65 \%$ & 3 & $1 / 4$ & 3 & $1 \times 1,2 \times 1$ or $1 \times 2$ & 3 & $1 / 2$ court \\
\hline 2 & $60 \%$ & 2 & Much rest & 2 & $3 \times 0$ and $2 \times 0$ & 2 & $1 / 3$ court \\
\hline 1 & $55 \%$ & 1 & Much rest & 1 & $5 \times 0$ and $4 \times 0$ & 1 & $1 / 4$ court \\
\hline
\end{tabular}




\subsubsection{Daily Training Load}

Once obtained the TL value for all the exercises, the next step was to develop the template for each training session (Table 2). The three main parts (columns) of the template were: exercise, minutes, and load. In the first column (exercise) the relevant exercise must be indicated. During the training, the Strength \& Conditioning Coach notes down the time of every exercise and includes it in the second column. Finally, in the last column, the software automatically calculates the TL of each exercise, taking into account its duration (minutes). At the end of the template, the total minutes and the total TL of the session can be seen. Time is the variable that must be most strictly controlled in this phase. As stated by other authors in relation with a series of TL tools [7-16], it is essential to know the duration of each exercise in order to calculate the TL. For example, in this session the total duration was 75 minutes, of which the players were active for only 61 minutes (49 minutes to do the exercises and 12 minutes to drink). The rest of the time was used to give instructions. The total TL was 69.7.

Table 2. Template used for every single training session

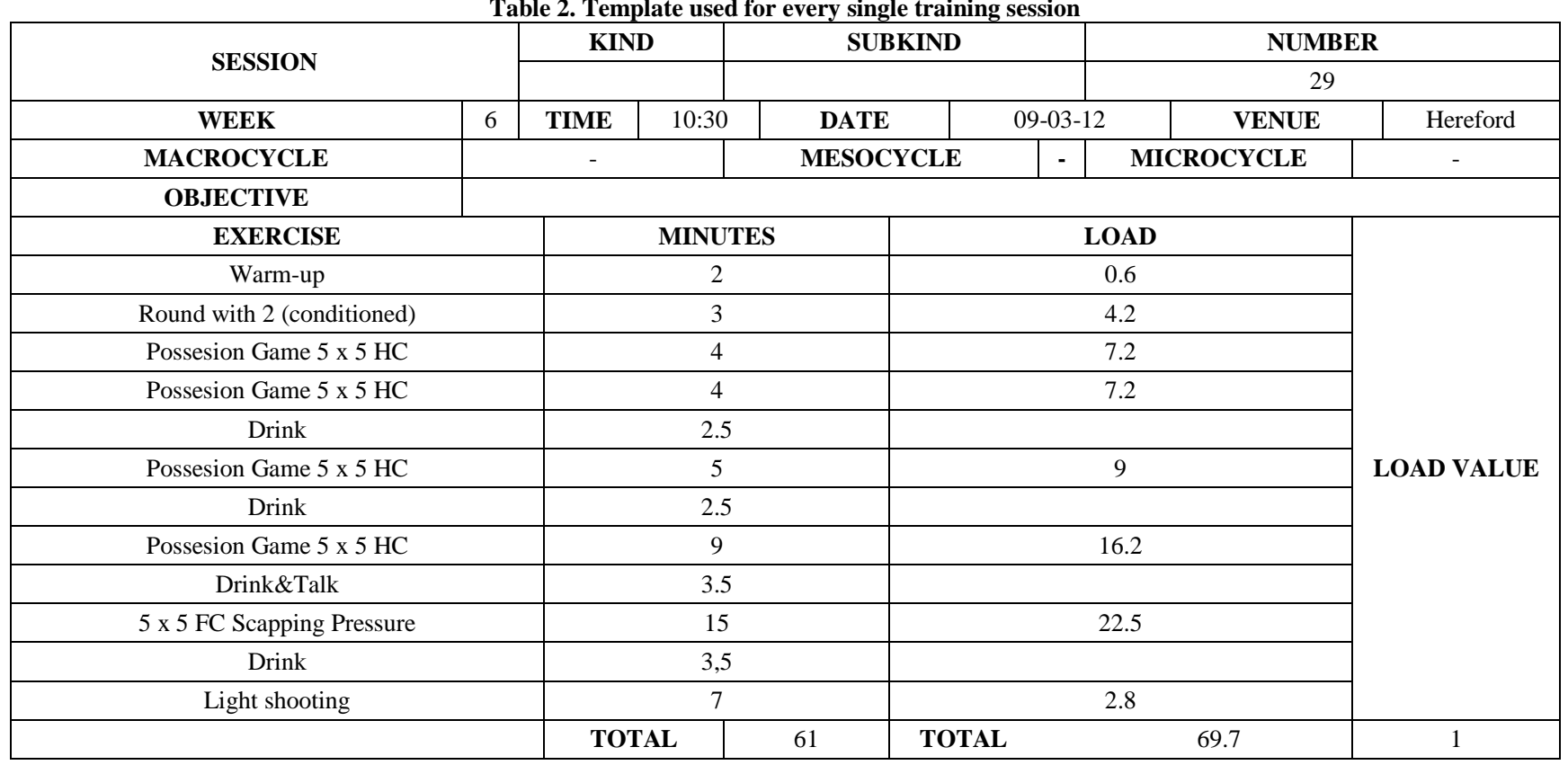

Since the total TL figure is too big to work with (i.e. $69,7)$, the sessions were classified in 8 different types: tactical or shooting session corresponds to level 0.5 (total TL $<50$ ); technical 1 or pre-game refers to level 1 (total $\mathrm{TL}<70$ ); technical 1.5 goes with level 1.5 (total TL < 90); technical 2 corresponds to level 2 (total TL $<110$ ); technical 2.5 goes with level 2.5 (total TL $<130$ ); technical 3 is level 3 (total TL $<150$ ); technical 3.5 refers to level 3.5 (total TL $<170$ ); and technical 4 or game is level 4 (total TL >170) (Table 3). Thus, a session with a total TL of 69.7 is considered to be a technical 1 session. Besides, intensity was calculated with the equation: intensity $=$ training load/duration. The research period covered the training load of a total of 50 tactical/technical sessions. Therefore, a total number of 800 individual training sessions were analysed (50 sessions $x 16$ players). If one player did not perform the whole session, the training load recorded was the load achieved until that moment.

Table 3. Table with the equivalences for the sessions.

\begin{tabular}{|c|c|c|}
\hline SESSION NAME & TL & POINTS \\
\hline Tactical/Shot & 0 & 0,5 \\
\hline Technical 1(pre-game) & 50 & 1 \\
\hline Technical 1,5 & 70 & 1,5 \\
\hline Technical 2 & 90 & 2 \\
\hline Technical 2,5 & 110 & 2,5 \\
\hline Technical 3 & 130 & 3 \\
\hline Technical 3’5 & 150 & 3,5 \\
\hline Technical 4 & 170 & 4 \\
\hline
\end{tabular}

\subsubsection{Rating of Perceived Exertion}

The RPE was measured using the 6-20 Borg scale [31]. Each player's session-RPE was collected about 30 min after each training session to ensure that the perceived effort was referring to the whole session rather than the most recent exercise intensity. All players were taught and familiarised with this scale for rating perceived exertion during the 2 weeks prior to the start of the study. In the procedure, the player is shown the scale and asked "How was your workout?", and they must give a single number representing the training session. The research period covered the session-RPE of a total of 800 individual tactical/technical sessions. If one player did not perform the whole session, the RPE recorded was the number given at the moment when the player withdrew from the session.

\subsubsection{Statistical Analyses}

All data are presented as mean \pm standard deviation (s). The relationships between the session-RPE and the heart rate with the various variables given by the FUTLOC tool were analysed using Pearson's product moment correlation. Fleiss's [32] evaluation defines concordance of variables as excellent when the correlation coefficient is $>0.75$, good when it is $0.60-0.74$, acceptable when 0.40 .0 .59 , and poor when $<0.40$. In the present study there were 3 variables with an excellent correlation (sessionRPE with intensity, training load and equivalent training load). There were no variables with a poor correlation. 


\section{Results}

The players' physical and anthropometrical characteristics were as follows (mean \pm s): an age of $24.75 \pm 3.36$ years old, a height of $176.21 \pm 0.70 \mathrm{~cm}$, a weight of $71.50 \pm$ $8.18 \mathrm{~kg}$, a Body Mass Index (BMI) of $23.17 \pm 2.22$, and an indirect $\mathrm{VO} 2 \mathrm{max}$ of $60.11 \pm 2.99 \mathrm{ml} / \mathrm{kg} / \mathrm{min}$, calculated from the 20-meter shuttle run test.
The distribution of the analysed technical/tactical sessions $(n=800)$ organised by their type is presented in Table 4, which also includes mean $\pm \mathrm{s}$ of session duration, training load, and intensity obtained from every type of training session. The Pearson's product moment correlation between the means of intensity, RPE and equivalent training load showed an excellent concordance (>0.75). Practices averaged $79.99 \pm 18.70 \mathrm{~min}$.

Table 4. Type of sessions analysed (total data analysed $=800)($ mean $\pm s)$

\begin{tabular}{ccc|ccccc}
\hline \multicolumn{3}{c}{ Training Session Characteristics } & \multicolumn{4}{c}{ Analysed Training Session (mean \pm s) } \\
\hline Session Type & Equivalent Training Load & Training Load & $\mathbf{n}$ & Session Duration (m) & Training Load & Intensity & RPE \\
\hline Tactical/Shot & 0.5 & $0-49$ & 48 & $50.67 \pm 7.37$ & $27.20 \pm 17.18$ & $0.55 \pm 0.37$ & $7.83 \pm 1.27$ \\
Technical 1(pre-game) & 1 & $50-69$ & 96 & $64.50 \pm 10.95$ & $57.03 \pm 8.16$ & $0.90 \pm 0.19$ & $9.68 \pm 1.20$ \\
Technical 1.5 & 1.5 & $70-89$ & 112 & $70.08 \pm 13.31$ & $79.99 \pm 5.07$ & $1.18 \pm 0.23$ & $11.97 \pm 1.40$ \\
Technical 2 & 2 & $90-109$ & 112 & $80.00 \pm 10.15$ & $102.59 \pm 5.30$ & $1.30 \pm 0.18$ & $12.64 \pm 0.79$ \\
Technical 2.5 & 2.5 & $110-129$ & 112 & $86.42 \pm 14.29$ & $116.64 \pm 7.09$ & $1.37 \pm 0.17$ & $12.83 \pm 0.37$ \\
Technical 3 & 3 & $130-149$ & 112 & $85.25 \pm 10.25$ & $136.85 \pm 3.68$ & $1.61 \pm 0.15$ & $13.45 \pm 0.28$ \\
Technical 3.5 & 3.5 & $150-169$ & 96 & $96.00 \pm 10.20$ & $156.00 \pm 4.34$ & $1.63 \pm 0.16$ & $13.90 \pm 0.27$ \\
Technical 4 & 4 & $>170$ & 112 & $105.00 \pm 2.40$ & $186.21 \pm 3.40$ & $1.77 \pm 0.03$ & $14.03 \pm 0.66$ \\
\hline
\end{tabular}

Session-RPE correlation with the variables given by the FUTTLOC tool for the 800 individual training sessions were as follows: the session-RPE had an excellent correlation with intensity $(\mathrm{r}=0.75)$, training load $(\mathrm{r}=0.77)$ and equivalent training load $(\mathrm{r}=0.77)$.

\section{Discussion}

The purpose of this research was to develop and investigate the potential correlation and therefore validate a new, inexpensive, easy, non-invasive, real time tool to control and monitor training load in futsal: the FUTLOC tool. More specifically, the correlations between the training load obtained from the FUTLOC tool and the players' session-RPE were analysed with the aim of validating the new method. The present study is the first to apply the FUTLOC tool and the players' session-RPE. The correlations found (ranging from 0.71 to 0.97), classified as excellent and good [32], confirmed that the FUTLOC tool may be an adequate and useful method to control and monitor training load in futsal.

The variables obtained from the FUTLOC tool (intensity, training load, and equivalent training load) had high correlation values with the session-RPE ( $\mathrm{r}=0.75$; $\mathrm{r}=0.77 ; \mathrm{r}=0.77$, respectively) in the 800 individual training sessions. These high correlations, obtained with a method (session-RPE) that has been proved to be adequate to control and monitor training load in team sports [7,21,33], allow to confirm that the FUTLOC tool may be a good instrument to measure training load in futsal. In the same way as the Borg scale (RPE) is considered to be a global indicator of exercise intensity, for it includes both physiological (oxygen uptake, heart rate, ventilation, beta endorphin, circulating glucose concentration, and glycogen depletion) and psychological factors [34], the FUTLOC tool also covers the training load components (volume, intensity, density, and complexity) and the training load dimensions (cognitive, metabolic, and neuromuscular) proposed by Refoyo [28].
To sum up the validation, the variables obtained from the FUTLOC tool (intensity, training load and equivalent training load) were correlated to the training load previously calculated with the Foster et al. $[6,20]$ method (training load $=$ session-RPE $\mathrm{x}$ session duration in minutes). The values obtained were $r=0.71 ; r=0.91 ; r=0.91$, respectively. These correlations between the FUTLOC tool and a method already validated and contrasted scientifically in a team sport (i.e. the Foster et al. [6,7] method) show the validity of the FUTLOC tool to control and monitor training load in futsal players.

Now that all the previous correlations have proved that the FUTLOC tool may be a useful method to control and monitor the training load in futsal, the next step would be to validate the 8 different types of sessions established by the training load range (Tactical/Shot 0.5 , Technical 1 or pre-game session, Technical 1.5, Technical 2, Technical 2.5, Technical 3, Technical 3.5, and Technical 4). Basically, and in the same line as the 6-20 Borg scale is a range of numbers and verbal anchords that corresponds roughly to a heart rate range of $60 \mathrm{bpm}$ for number 6 to 200 bpm for a score of 20 in healthy people (approximately 30 years of age) [31], one of the purposes of this study was to investigate if the type of sessions established could correspond to a session-RPE value. For this purpose, average intensity and session-RPE, were correlated with the equivalent training load. The results obtained showed strong correlations $(r=0.97 ; \mathrm{r}=0.92$, respectively) (Table 4). Therefore, the value of RPE related to any type of session may be established (i.e. Technical 1.5 session corresponds to a total training load of 70-89 and a session-RPE of $11.97 \pm 1.40$ ).

The previous data analysis and correlations obtained in this study suggest that the FUTLOC tool is easy to use, quite reliable, and consistent with subjective (RPE), which provides enough support to use it as a method of controlling and monitoring training load in futsal practices in real time. The FUTLOC tool may offer a mechanism for quantitating the exercise intensity component and allows calculation of a single number representative of the 
combined intensity and duration of the training sessions while the practice is occurring.

Due to the fact that the FUTLOC tool has been developed with the Excel software programme (Microsoft Corporation, U.S.), a daily exercise score is created. An exercise diary will show the daily and overall weekly training load, the latter being presented graphically, allowing the coach to have a visual impression of the periodisation plan. Finally, the originally planned periodisation with the daily and weekly training load is compared with the real daily and weekly load achieved.

\section{Conclusions}

To conclude, based on the results in this study and the literature reviewed, the FUTLOC tool seems to be a good method to control global internal training load in futsal. This method does not require any expensive equipment and may be very useful and convenient for coaches to monitor the internal training load of futsal players. Furthermore, the present results suggest that the FUTLOC tool may assist in the development of specific periodisation strategies for futsal teams. Finally, the FUTLOC tool offers real-time feedback to futsal coaches, so that they can monitor the training load evolution during the training session and be able to modify the session exercises or tasks with the aim to achieve the required or planned training load.

\section{References}

[1] A.J. Coutts, M.S. Aoki. Monitoring training in team sports. Olympic Laboratory: Technical Scientific Bulletin of the Brazilian Olympic Committe, 9 (2009) 2:1-3.

[2] P. Gamble. Periodization of training for team sports athletes. Strength and Conditioning Journal, 28 (2006) 5:56-66.

[3] V.G. Kelly, A.J. Coutts. Planning and monitororing training loads during the competition phase in team sports. Strength and Conditioning Journal, 29 (2007) 4:32-37.

[4] E.W. Banister, P. Good, G. Holman, C. L. Hamilton. Modelling the training response in athletes. In: Sport and Elite Performers. Laders MD ed. Champaign, IL: Human Kinetics, pp. 7-23, 1986.

[5] D. L. Costill, R. Thomas, R.A. Robergs, D. Pascoe, C. Lambert, S. Barr, W. J. Fink. Adaptations to swimming training: influence of training volume. Medicine and Science in Sports and Exercise, 23 (1991) 3:371-377.

[6] C. Foster. Monitoring training in athletes with reference to overtraining syndrome. Medicine and Science in Sports and Exercise, 30 (1998) 7:1164-1168.

[7] C. Foster, J.A. Florhaug, J. Franklin, L. Gottschall, L.A. Hrovatin, S. Parker, P. Doleshal, C. Dodge. A new approach to monitoring exercise training. Journal of Strength and Conditioning Research, 15 (2001) 1:109-115.

[8] E.W. Banister, T.W. Calvert, M.V. Savage, T. Bach. A systems model of training for athletic performance. Australian Journal of Sports Medicine, (1975) 7:57-61.

[9] E.W. Banister EW, T.W. Calvert TW. Planning for future performance: implications for long term training. Canadian Journal of Applied Sport Sciences, 5 (1980) 3:170-6.

[10] R.H. Morton, J.R. Fitz-Clarke, E.W. Banister. Modeling human performance in running. Journal of Applied Physiology, 69 (1990) 3:1171-1177.

[11] A. Lucía, J. Hoyos, A. Carvajal, J.L. Chicharro. Heart rate response to professional road cycling: The Tour de France. International Journal of Sports Medicine, (1999) 20:167-172.
[12] P.R. Hayes PR, M.D. Quinn. A mathematical model for quantifying training. European Journal of Applied Physiology, (2009) 106:839-847.

[13] S. Edwards. The heart rate monitor book. Sacramento: Fleet Feet Press, pp. 56-64, 1993.

[14] G. Iliuta, C. Dimistrescu. Criterii medicale si psihice ale evaluarii si conducerii antrenamentului atletitor. Sportul de Performanta, (1978) 53:49-64.

[15] I. Mujika, T. Busso, L. Lacoste, F. Barale, A. Geyssant, J.C. Chatard. Modelled responses to training and taper in competitive swimmers. Medicine and Science in Sports and Exercise, (1996) 28:251-158.

[16] F.D. Desgorces, X. Sénégas, J. Garcia, L. Decker, P. Noirez. Methods to quantify intermittent exercises. Applied Physiology, Nutrition and Metabolism, (2007) 32:762-769.

[17] S. Saalasti. Neural network for heart rate time series analysis. Academic Dissertation, University of Jyväskylä, Finland. 2003.

[18] H.K. Rusko, A. Pulkkinen, S. Saalasti, E. Hynynen, J. Kettunen J. Pre-prediction of EPOC: a tool for monitoring fatigue accumulation during exercise? Medicine and Science in Sports and Exercise, 35 (2003) 5:S183.

[19] Firstbeat Technologies Ltd. Indirect EPOC prediction method based on heart rate measurement (White Paper). Jyvaskyla. 2007.

[20] L. Anderson, T. Triplett-McBride, C. Foster, S. Doberstein, G. Brice. Impact of training patterns on incidence of illness and injury during a women's collegiate basketball season. Journal of Strength and Conditioning Research, 17 (2003) 4:734-738.

[21] F. M. Impellizzeri, E. Rampinini, A.J. Coutts, A. Sassi , S.M. Macora. Use of RPE-based training load in soccer. Medicine \& Science in Sports \& Exercise, 36 (2004) 6:1042-1047.

[22] K.M. Stagno, R. Thatcher, K.A. Van Someren. A modified TRIMP to quantify the in-season training load of team sport players. Journal of Sports Science, 25 (2007) 6:629-634.

[23] A.J. Coutts, E. Rampinini, S.M. Marcora , C. Castagna, F.M. Impellizzeri. Heart rate and blood lactate correlates of perceived exertion during small-sided soccer games. Journal of Science and Medicine in Sport, (2009) 12: 79-84.

[24] A. Moreira, C.G. de Freitas, F.Y. Nakamura, M.S. Aoki. Session RPE and stress tolerante in young volleyball and basketball players. Brazilian Journal of Kinantropometry and Human Performance, 12 (2010) 5:345-352.

[25] D. Berdejo-del-Fresno. Periodisation and training load control in futsal. Proc. of the Intensive Programme on Sport Performance: A Lifespan Challenge (Rome, Italy), 2012.

[26] T.G. Lohmann, A.F. Roche, R. Martorell. Anthropometric standardization reference manual. Champaign, IL: Human Kinetics. 1988.

[27] D. Berdejo-del-Fresno, J.M. González-Ravé. Development of a new method to control and training load in basketball: the BATLOC Tool. Journal of Sport and Health Research, 4 (2012) 1:93-102.

[28] I. Refoyo. La decisión táctica de juego y su relación con la respuesta biológica de los jugadores: una aplicación al baloncesto como deporte de equipo. PhD Thesis. Universidad Complutense de Madrid. 2001.

[29] R. Singer. Motor learning and human performance. New York. McMillan, pp. 245-264. 1980.

[30] F. Sánchez-Bañuelos, L.M. Ruiz-Pérez. Optimización del aprendizaje de la técnica. High Sport Performance Master. Spanish Olympic Committee and Universidad Autónoma de Madrid. 2000.

[31] G. Borg. Perceived exertion as an indicator of somatic stress. Scandinavian Journal of Rehabilitation Medicine, 2 (1970) 2-3, 92-98.

[32] J.L. Fleiss. The design and analysis of clinical experiments. New York, NY: Wiley. 1986

[33] V. Manzi, S. D’Ottavio, F.M. Impellizzeri, A. Chaouachi, K. Chamri, C. Castagna. Profile of weekly training load in elite male professional basketball players. Journal of Strength and Conditioning Research, 2010; 24 (2010) 5, 1399-1406.

[34] W.P. Morgan. Phychological factors influencing perceived exertion. Medicine and Science in Sports and Exercise, (1994) 26, 1071-1077. 